\title{
Investigación \\ Paisajes coloniales en el Bajo Guadalquivir. Origen, evolución y carácter patrimonial
}

Águeda A. Villa Diaz y Juan F. Ojeda Rivera

Geógrafos. Grupo de Investigación Estructuras y Sistemas Territoriales (GIEST). Universidades de Sevilla

\section{Resumen}

Los planes de colonización llevados a cabo en España durante un largo proceso que se consolida e intensifica en el siglo XX han influido en la modificación y evolución de los territorios destinatarios de tal planificación estatal. Los procesos de intervención generan unos paisajes que incluso podrian llegar a constituirse en elementos más conformadores de identidad comunitaria. En este texto, los autores analizan los planes de colonización agraria y forestal realizados en el Bajo Guadalquivir durante la etapa franquista a partir del estudio de tres territorios paradigmáticos de paisajes coloniales: los forestales del Abalario, los arroceros de Isla Mayor y los regados del Viar. Águeda A. Villa y Juan F. Ojeda recorren la historia, origen y evolución de estos territorios de colonización para reflexionar sobre la posible identificación de las poblaciones con unos paisajes configurados a partir de intereses económicos y políticos ajenos a ellos, así como sus posibles consideraciones como patrimonios comunitarios.

\section{Palabras clave}

\section{Arquitectura}

Colonización agraria

Franquismo

Guadalquivir, Zonas Regables del

Paisaje forestal

Paisaje rural

Patrimonio forestal

Pueblos de colonización Viviendas rurales

\section{Introducción}

El paisaje no es sólo una categoría compleja porque en él se relacionen formas objetivas y percepciones subjetivas, sino porque, además, es el resultado material de un secular proceso de vinculación de una comunidad con su medio -acumulador o totalizador histórico- $y$, también, la consecuencia de un proceso de transformación cultural de espacios creativamente contemplados o percibidos -artialización-. En función de todo ello, los paisajes se constituyen en patrimonios sociales, históricos y culturales de sus diferentes comunidades humanas y, como tales, se caracterizan por ser, a la vez, patrimonios materiales -componentes y flujos- e inmateriales -percepciones y miradas-, permanentes -elementos y percepciones durables- y dinámicos -elementos y percepciones cambiantes-.

La potencia de un paisaje, como patrimonio de una comunidad, es tanto mayor cuanto mayor sea su complejidad -más componentes, más relaciones, más historia- su resiliencia -más adaptable a superar situaciones de estrés-y su aceptación social -más identitario, más connotado, más simbólico-, hasta el punto de que podría llegarse a considerar que un espacio geográfico demasiado simple y reciente, especialmente vulnerable y poco reconocido socialmente constituiría un protopaisaje o un paisaje que está en proceso de hechura -in fieri, que dirian los latinos-

Estas páginas pretenden presentar los elementos y percepciones de algunos paisajes creados en el Bajo Guadalquivir por unos específicos planes estatales de colonización agraria y forestal implantados en la España autárquica y desaparecidos o consolidados con el desarrollismo de los años 60 y 70 del siglo XX. El estado franquista, ilegitimo e internacionalmente boicoteado, intenta convertir la necesidad en virtud Ilegando a considerar la obligada autarquía como un distintivo propio y tiene que resolver algunos abastecimientos básicos (alimentos, madera, papel) a través de la implantación de colonias de explotación y de poblamiento en algunos de sus propios territorios hasta el momento improductivos (arenales y marismas) o claramente mejorables en sus productividades (riberas béticas). De aquellas colonias, unas perderán su funcionalidad y desaparecerán con la apertura del país a los mercados internacionales, pero otras tenderán a consolidarse con la intensificación de sus monoproducciones, con la diversificación de sus estrategias productivas y, sobre todo, con las progresivas identificaciones de las poblaciones coloniales con sus respectivos nuevos paisajes.

Los paisajes coloniales, tal como aquí son entendidos, recogen, pues, distintos elementos presentes en las acepciones que el sustantivo colonia tiene en el diccionario de la Real Academia y se caracterizarian por ser los resultados de la puesta en valor de unos 


\section{Investigación \\ Paisajes coloniales en el Bajo Guadalquivir. Origen, evolución y carácter patrimonial \\ Águeda A. Villa Díaz Juan F. Ojeda Rivera}

espacios hasta entonces incultos mediante nuevas producciones, sus poblamientos por personas traidas de fuera, así como sus ordenaciones territoriales a través de planes y leyes especiales. $Y$ todo ello dictado desde el exterior del propio territorio y en función de las necesidades de las metrópolis, o de las aquí llamadas "necesidades nacionales". Dichas necesidades marcan los tipos de coIonia y, consecuentemente, sus paisajes, de tal forma que puede hablarse de colonias de explotación -territorios con recursos cuyas explotaciones cubren abastecimientos metropolitanos, por ejemplo, los espacios coloniales tropicales surten a las metrópolis de materias primas ultramarinas básicas y fácilmente producidas alli (cacao, café, azúcar...)-y de colonias de poblamiento -espacios de relativo confort climático, en los que se instala una población metropolitana sobrante, que juega el triple papel de mano de obra productiva, representación cultural y comunidad consumidora-.

Los paisajes coloniales de explotación se caracterizan porque están basados en una primera consideración del espacio geográfico como barato y propicio para explotar uno de sus recursos y obtener de tal explotación producciones masivas y coyunturales, sin preocuparse del orden de todo el territorio. Ello suele conducir, por una parte, a unos puzzles de paisajes-islas de monoproducción, que no tienen en cuenta la relación de las energías y materias superexplotadas en cada ecosistema con el mantenimiento de otros ecosistemás limitrofes; por otra parte, al sostenimiento de una sociedad muy dependiente del exterior y para la que no son fundamentalmente útiles los productos obtenidos, con lo que adquieren especial relevancia en estos paisajes las infraestructuras y equipamientos para la exportación - almacenes o caminos de saca- y, por último, a la consolidación de una estructura social muy dual -colonos extranjeros / operarios autóctonos o inmigrados- cuyo reflejo paisajístico se suele encontrar en la dualidad de hábitats.
Por su parte, los paisajes coloniales de poblamiento suponen unas transformaciones estructurales de los espacios, convertidos no sólo en territorios productivos, sino sobre todo en sostén de las poblaciones allí llegadas o llevadas. La intencionalidad de crear estructuras estables y favorecer la permanencia caracteriza a estos paisajes frente a los anteriores por ser más variopintos, más autoabastecedores y más homogéneos en sus hábitats.

Teniendo en cuenta el anterior marco de referencias, surge una primera interrogante: ¿Hasta qué punto los paisajes coloniales andaluces que aquí se van a presentar -los forestales del Abalario, los arroceros de Isla Mayor y los regados del Viar- han ido constituyéndose en verdaderos patrimonios de unas comunidades humanas que pueden formar parte de ellos -si todavía permanecen alli-, pero que nada decidieron respecto de su creación y de los caracteres de su propia configuración, sino que sólo jugaron el papel de mano de obra útil y barata para la explotación exógena de unos recursos muy específicos o de población pionera trasladada obligada o voluntariamente a aquellos nuevos territorios?

A través de las sucesivas presentaciones de antecedentes, procesos, componentes o elementos principales y percepciones de aquellos paisajes paradigmáticos de lo colonial en este mundo del Bajo Guadalquivir, esperamos ir respondiendo a la cuestión planteada.

\section{Paisajes forestales de las arenas litorales. El ejemplo de El Abalario}

En las arenas del sureste de la provincia de Huelva, la creación del nuevo paisaje sería de responsabilidad pública, aunque se funda-
Juan Villa. Pues valdrá como ejércitos el miedo. Novela inédita, 2004, pp.14-16. Fragmentos

¡Mesopotamia!, amigo Bernabé, ¡Meso- potamós! Entre dos ríos. ¡Pero qué sabes tú de eso! ¿verdad? A levante el río Betis, no Guadalquivir, nombre semítico, sarraceno, con el que nunca debió ser bautizado, aunque luego bien que se lo hicimos pagar. A poniente la ría del Tinto y el Odiel, cuna del Imperio, de donde en una edad dichosa partieron nuestras naves y ganaron para la Patria y para la Fe un continente pletórico de rios y montañas ni imaginadas siquiera. Ésta será mi tierra, la antigua Tartessos, y como Gerión, en ella construiré mi ciudad de oro porque como el oro relucirán los corazones de su gente, iya nos encargare- mos nosotros! Esta zafia planicie que se extiende a nuestros pies, donde ahora campean a sus anchas las bestias y las plagas, un dia no muy lejano será un vergel, Bernabé, un lugar en el que el hombre, en concierto con las leyes de Dios y el Movimiento Nacional, verá surgir poblados limpios y alegres, con calles anchas de aire moderno, escuelas, hospitales, y trabajo, mucho trabajo, para que un bosque de eucaliptos de rectas ringleras que se pierdan en el horizonte abarroten de madera la fábrica de celulosa que será el corazón de este Edén. La fábrica de la que saldrá el papel en el que escribiremos la historia de la España Nueva.

Imposible, Bernabé, es sólo lo que no se intenta. Todo hombre debe tener claro su fin en este valle de lágrimas, y perseguirlo, 


\section{Investigación \\ Paisajes coloniales en el Bajo Guadalquivir. Origen, evolución y carácter patrimonial \\ Águeda A. Villa Díaz Juan F. Ojeda Rivera}

viamente intervinientes y el Patrimonio Forestal del Estado continuó con los mismos patrones, eso sí, aumentando el número en función de la gran extensión transformada. En relación con los asentamientos, aparecieron las más importantes diferencias, ya que mientras los levantados por las compañias se resolvían en núcleos pequeños de carácter transitorio y estacional y exclusivamente funcionales como estancias de la mano de obra necesaria en cada momento; los asentamientos públicos se van a desarrollar, en principio, como verdaderos poblados que cubririan todas las necesidades de sus habitantes y tendrían vocación de permanencia, generando una sociedad nueva en función de los valores del nacional-catolicismo.

Tales intenciones, así como la idea de jerarquía, quedan bien reflejadas en los recién nacidos poblados forestales que se levantan atendiendo a un modelo de campamento con pocas variantes: grupos de viviendas iguales enfrentadas en calles cortas y rectas; completadas con zonas que acogian edificios o equipamientos vinculados a la producción (almacenes, talleres, oficinas, viveros, arboretos, semilleros) o a los servicios (escuela, cantina, enfermería, lavadero) y destacándose bien del conjunto -a modo de acrópolisla iglesia y una o varias viviendas dedicadas al jefe y al resto del personal técnico y administrativo (los mandos).

Las ideas de "misión" y de "obra" eran claramente perceptibles en el conjunto paisajístico recién construido donde los poblados perfectamente intercomunicados aparecian como los hitos fundamentales y estructurantes. Por otra parte, la creación de aquel paisaje nuevo, productivo y habitado fue determinante para la identidad de este espacio, siendo en aquel momento histórico -mediados del siglo XX- cuando estos arenales baldios comienzan a percibirse como un área de destino común conocido por "El Patrimonio".
Pero, siguiendo el proceso clásico de las colonias de explotación, aquel Patrimonio se fue desmoronando al socaire de unos tiempos que también cambiaban de signo, de necesidades y de paradigmas: la autarquía se troca en apertura y desarrollismo, las producciones primarias dan paso a la industrialización y a la conservación de la naturaleza, el clorofilismo tiende a convertir al eucalipto en enemigo del futuro. Todo converge en la dirección de convertir de nuevo aquel ilusorio Patrimonio en verdadero espacio vacio, barato y baldío que espera nuevas experimentaciones turístico-naturalísticas. Pero de aquel nuevo paisaje colonial quedan hoy algunos patrimonios reales como son los poblados de Cabezudos y Abalario, el vivero y poblado de la Mediana, el arboreto de El Villar, la fábrica de Cabezudos... que constituyen el conjunto testimonial ilustrativo de un proceso colonial periclitado.

\section{Paisajes agrarios de las marismas arroceras. El ejemplo de Isla Mayor}

Las intervenciones que dieron lugar al nacimiento de estos nuevos paisajes marismeños -como los de las arenas, que acaban de presentarse- se concretan en el ecuador del siglo XX, pero cuentan con unos antecedentes desarrollados en el XVIII y XIX y en las primeras décadas del mismo XX, que dibujaban pautas comunes en sus respectivos procesos de conformación.

Hay que situarse en el contexto ideológico y científico de la ilustración y en la voluntad decimonónica de sanear y poner en producción espacios marginales, tanto por su escasa productividad como por sus malas condiciones para el buen desarrollo de la vida humana, para comprender cómo marismas y arenales participan de una imagen negativa y publicitada desde finales del siglo XVIII, sois muy pocos, y los que vengan, que serán muchos. Este espíritu que tanta falta os hace es el que nos lleva a formar sociedades cuyo fin es el bien común, que nunca debe ir en contra de los Mandamientos de la ley de Dios, de la Iglesia y de los deberes propios de cada estado. La sociedad, Bernabé, debe ser fuerte y correctora de todo vicio: del egoísmo, de la avaricia, del orgullo, del desprecio al superior, del odio violento del inferior, del goce inmoderado que conduce a placeres degradantes, funestos para todas las agrupaciones humanas, eso es lo que debe entrar en vuestras cabezas, por las buenas o por las malas. Hoy la Patria nos exige este esfuerzo de gigantes y ningún holandés, suizo o cartaginés o de donde quiera que sea podrá impedir que los divinos designios se cumplan porque el plan del Altísimo y las necesidades de España están muy por en- cima de cualquier empeño personal y egoista. Nada necesitamos de nadie, nuestra misma tierra nos proporcionará el pan necesario para vivir y la energía para reconstruirla y limpiarla de las malas hierbas, por mucho que se escondan cobardes bajo las piedras, como serpientes traidoras. $Y$ nada nos tiene nadie que enseñar porque tenemos la más grande de las Historias y la más santa de las tradiciones, nada malo nos sucederá si no nos apartamos de ellas. No olvides esto. Tú serás mi fedatario, buen Bernabé, hoy y aqui comienza el futuro. 
desde ámbitos técnicos y literarios (descripciones geográficas, viajeros...): “...terrenos pantanosos y encharcadizos...", “...grandes extensiones insalubres desiertas, dominadas por la silice en arenales vivos y muertos...", "...terrenos incultos y abandonados, anegados, despreciables y de escasísimo valor...".

En tales marcos de referencia, la desecación y bonificación de las marismas -como el dominio de los arenales, mediante la fijación de las dunas móviles- se presentan como obras justificadas por razones perentorias de salubridad o de cosmología. En función de ello, el Estado debe ser el encargado de realizarlas directamente o bien de impulsarlas y facilitarlas, complementando las tareas de grandes empresas extranjeras propietarias o concesionarias de las tierras que -a modo de compañias coloniales- jugaron un papel decisivo en la conformación de estos nuevos paisajes. La presencia de estas compañías responde a la atracción de capitales extranjeros, iniciada en el siglo XIX y mantenida en las primeras décadas del $X X$, y da lugar a una forma primitiva de colonialismo concebida entonces como mecanismo de modernización y apertura del país. Muchos son los ejemplos de este sistema colonial mercantil en Andalucía Occidental, vinculados a la minería, a la vitivinicultura o a ciertos servicios públicos.

En la Isla Mayor, desde principios del siglo XIX se habían acometido obras para facilitar la navegación (Compañía de Navegación del Guadalquivir, 1918) y las actividades agrícolas e industriales (Compañia de las Islas del Guadalquivir 1927). En plena Guerra Civil, en 1937, y ante la acuciante falta de alimentos, se aborda la puesta en cultivo de arroz de la Isla Mayor, recogiendo el éxito obtenido por la "Compañía de las Islas del Guadalquivir" conocida como de "Los Ingleses" en sus experimentos con este cultivo. En esa fecha, entra en escena una empresa andaluza, "R. Beca y Cía.-Industrias Agrícolas", que se convertirá en la principal concesionaria de las obras y otras tareas colonizadoras para la conversión de la Isla en un inmenso arrozal.

En la construcción de este nuevo paisaje marismeño, el proceso se inicia con la polderización, que bonifica las tierras, desecándolas y desalinizándolas. De esta forma, se hace efectiva una pretensión secular de generar paisajes agrícolas sobre aquellas arcillas muy dominadas por la estacionalidad y la inundación natural, en las que tradicionalmente habian existido hitos productivos agrícolas -matos, huertas y hatos- que jalonaban aquel ambiente hostil a las producciones agrarias de la predadora y pecuaria marisma.

Los actuales poblados marismeños son continuación de los alojamientos levantados desde 1927 por las compañias en distintos lugares, como Colinas -situado en la vera a modo de acrópolis, que debía acoger al personal técnico y administrativo de la empresa- o los pequeños asentamientos isleños de El Puntal, El Rincón de Los Lirios, Queipo de Llano y Reina Victoria, además del primitivo poblado de Alfonso XIII, que se proyecta como tal desde el primer momento, aunque sólo se construye en una primera instancia la iglesia, las oficinas de la compañia y algunos grupos de viviendas, convirtiéndose ya desde entonces en el asentamiento más importante. Tales poblados, como formas de hábitat permanente en Las Marismas y, por tanto como escenarios principales de los cambios sociales que han dado lugar a su realidad actual, son unos elementos muy significativos de este paisaje si bien no pueden separarse ni entenderse más que como parte del arrozal, en cuyo conjunto aparecen a modo de hitos que interrumpen la monotonía del cultivo aportando cierta verticalidad y la certeza de la definitiva humanización de estas marismas. Con posterioridad a la Guerra Civil y paralelo al éxito y afianzamiento del arrozal, se reestructurará todo el poblamiento de Isla Mayor orientándolo hacia la progresiva concentración de una población cada vez más numerosa y venida desde destinos variados. Será el Instituto Nacional de la Vivienda (INV) el organismo encargado de concebir poblados "integrales" ampliando y dotando de edificios públicos y administrativos a algunos de los existentes, sobre todo El Puntal que, con su nueva denominación de Villafranco del Guadalquivir, multiplicaría su desarrollo hasta convertirse recientemente en la cabecera de un municipio independiente que toma otro nombre Isla Mayor- por decisión ya democrática de sus ciudadanos (esta cuestión puede ser ampliada en p. 52-53 y p. 126).

La superación de las sucesivas crisis del arroz, la aparición y desarrollo del cangrejo rojo de río y sus correspondientes mercantilización y asimilación gastronómica, así como las más recientes actividades de turismo rural han ido generando procesos de complejidad, resiliencia y aceptación social de estos nuevos paisajes marismeños, cuyos colonos y sus descendientes fueron reinventándolos e identificándose con ellos a partir de un conjunto de signos y ritos (edificios, hitos, fiestas, gastronomía, etc.) que los han conformado como sus propios patrimonios paisajísticos.

\section{Paisajes agrarios de las zonas regables del Guadalquivir. El ejemplo del Viar}

Las colonizaciones agrarias de las zonas regables del propio tronco del Guadalquivir y de algunos de sus afluentes (Bembezar, Viar, Guadamellato...), llevadas a cabo en la primera mitad del siglo XX, deben ser enmarcadas en unas políticas generales de colonización 


\begin{tabular}{|l|}
\hline Investigación \\
Paisajes coloniales en el \\
Bajo Guadalquivir. Origen, \\
evolución y carácter \\
patrimonial \\
\\
Águeda A. Villa Díaz \\
Juan F. Ojeda Rivera \\
\hline
\end{tabular}

en las que convergen criterios e intervenciones técnicas vinculadas a la hidráulica con planteamientos y actuaciones socio-económicas encaminadas, teóricamente, a la consecución de unas estructuras de propiedad agraria más igualitarias y, a la vez, más propicias al aumento de la productividad y la competencia.

Desde fines deI XIX, se venía considerando por los regeneracionistas (M. Picavea, J. Costa...) que la riqueza de España debía basarse en la regulación, control y buen uso de sus aguas como mecanismo primordial de multiplicación de sus producciones agrícolas (el mito del agua o el agua bendita). Inmerso en aquel paradigma regeneracionista, se sustenta el Plan General de Obras Hidráulicas de Lorenzo Pardo (1902), cuyo objetivo es la regulación de las aguas superficiales de los principales ríos españoles con vistas a su mejor aprovechamiento energético y agrario.

Pero, además de por carencia de aguas reguladas y aprovechables, el campo español se caracterizaba también por la mala distribución de su estructura fundiaria, de manera que ni el débil y exiguo minifundio, ni el gran y extensivo latifundio constituian unidades adecuadas de explotación para elevar sustancialmente sus productividades agricolas. Las sucesivas desamortizaciones del siglo XIX no habian producido un efecto redistribuidor de tierras sino que, al contrario, habían consolidado el latifundismo y, ya en la charnela de los siglos XIX y XX, se explicita la conciencia de que tal latifundismo es uno de los grandes problemas que azotan al sur de España por su persistente actitud extensivista y despilfarradora. Las denuncias de la situación por parte de Gómez del Moral y de Pascual Carrión apuntan a la necesidad de ligar la política hidráulica con la de reparto de tierras, lo que resulta fundamental en la II República, cuyo Instituto de Reformas Agrarias (IRA) intenta conjugar expropiaciones y repartos con desarrollo de obras hidráulicas.

\section{Alfonso Grosso y Armando López Salinas. Bilbao: Albia Literaria, 1977. Fragmentos}

La Venta del Cruce es un lugar donde acuden los capataces, los agrónomos de la Confederación, los topógrafos, los técnicos de las Compañias que recorren la Isla en automóviles "Land Rover", con sus botos de campo y sus gorras de visera, midiendo, calculando, viendo la forma de sacar el máximo provecho a la gran sociedad anónima de la marisma.

Frente a la Venta, en el eucaliptal, los segadores, los mismos de la mañana otros quizás, esperan sentados sobre la hierva polvorienta, con las manos dejadas caer sobre las rodillas y la mirada perdida en el horizonte del arroz... (p.65)
2. Atín Aya. Poblado de Alfonso XIII. Fotografía. Fuente: Atín Aya. Marismas del Guadalquivir. Centro Cultural del Conde Duque, 2000

Tras la guerra civil, el Instituto Nacional de Colonización (INC) -organismo del Estado franquista- tecnocratiza los principios básicos de la política agraria descrita y pergeñada en España desde principios del siglo XX, preconizando la necesidad de hacer converger la sociedad campesina con el aumento de las productividades agrícolas. Las colonizaciones agrarias seguirán manteniendo, pues, los explícitos papeles de promocionar explotaciones familiares y de elevar la competitividad agrícola nacional, con matices más autárquicos (INC) o más productivistas (IRYDA) en función de los momentos políticos, aunque implícitamente, la promoción de explotaciones familiares en los nuevos regadíos béticos -yuxtapuesta a la permanencia de grandes explotaciones de las campiñas y vegas del Guadalquivir- otorgará a los colonos-jornaleros el papel de mano de obra barata, segura y cercana para aquellas grandes explotaciones y el de compañeros de viaje de latifundistas en los sindicatos verticales y las comunidades de regantes del régimen fascista.

En definitiva, los antecedentes y procesos de la colonización agraria a través de grandes zonas regables promocionadas por el Estado están enmarcados en unos discursos políticos que mezclan, por una parte, la obra pública hidráulica necesaria en un país húmedo y seco a la vez, por otra, la consolidación de agriculturas familiares inmersas en sociedades campesinas y, además, el aumento de la productividad agrícola mediante una promoción del intensivismo. Estos tres objetivos se convierten en otros tantos motores de todas las politicas agrarias de distinto signo -cada cual matizará la trilogía, destacando el carácter más afín- que se implementan en España durante el largo y convulso tiempo que media entre la restauración borbónica del XIX y la instauración de la democracia, a finales del $X X$. 


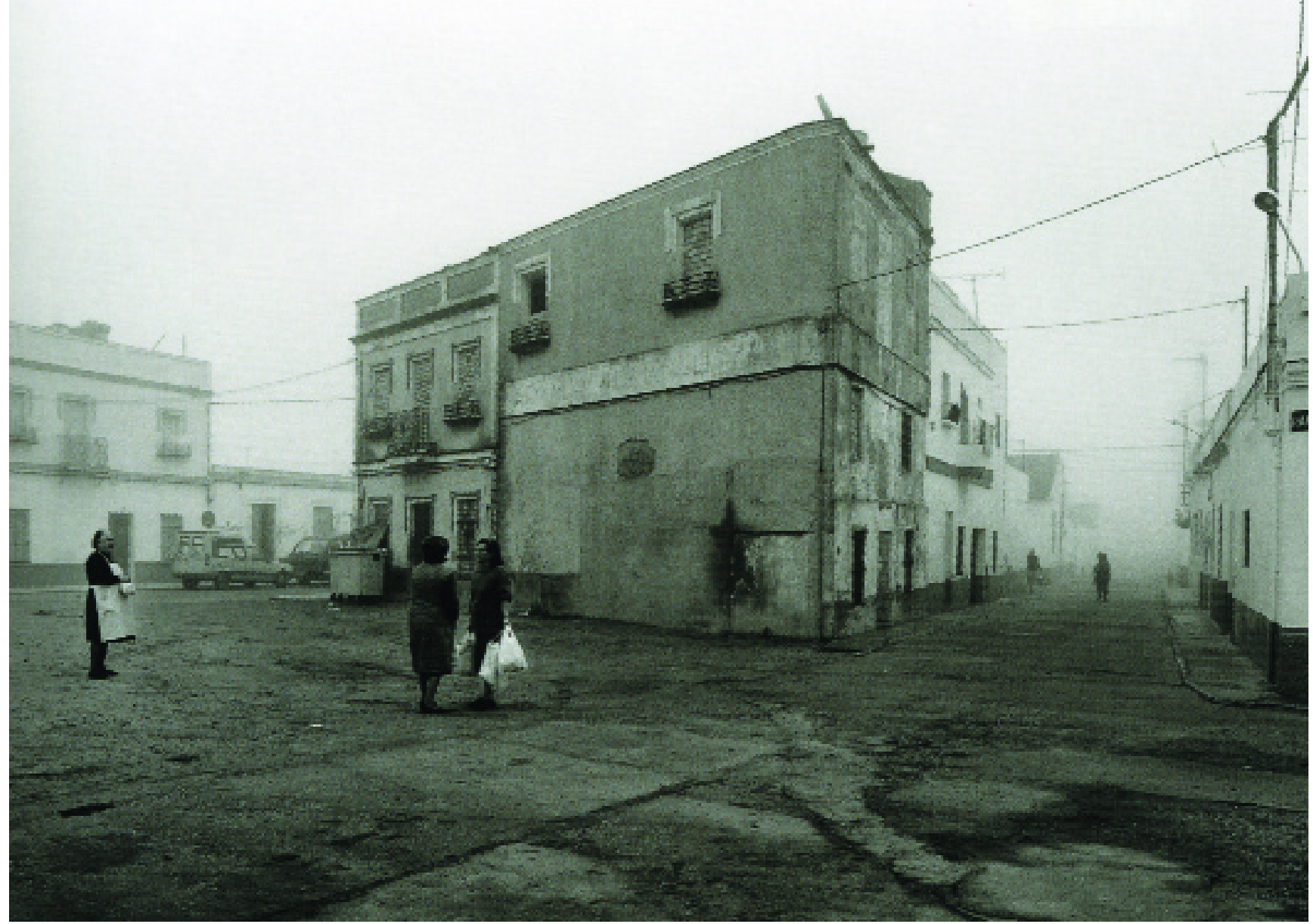

La zona regable del Viar -afluente del Guadalquivir por su margen derecha- se extiende por unas 12.000 has., que se encuentran situadas a $20 \mathrm{Kms}$. de la ciudad de Sevilla, lo que es considerado como una ventaja para una colonización agrícola porque tal cercanía induciría a producir intensivamente para abastecer a la urbe, que, a su vez, ofrecería mayores posibilidades de empleo alternativo a la mano de obra familiar. El origen de esta zona regable está en la inclusión, en 1907, de un embalse sobre el río Viar en el Plan General de Obras Hidráulicas y la realización efectiva de su infraestructura de riego, que se prolonga desde 1931 a 1960, en dos fases: La primera, desarrollada en la II República y caracterizada por la precipitación en el diseño general y en la realización de los primeros trabajos, lo que determinará una deficiencia estructural de la zona en el suministro de aguas. La segunda, se inicia en 1949 con la declaración de Zona de Inte- rés Nacional, la promulgación del Plan General de Colonización, las obras de infraestructura para el riego y el proceso de expropiación, que sólo afectó a 2.300 has., parceladas y distribuidas entre 397 colonos, que fueron ocupando las tierras entre 1953 y 1957.

En definitiva, la actuación del INC se circunscribe sólo al 20\% de las tierras de la zona regable y los nuevos colonos no llegan a representar ni un tercio de los propietarios de la misma. Las normas de expropiación condujeron a un cierto fraccionamiento de las previas fincas como estrategia familiar de mantenerlas en propiedad, pero no obstante subsisten grandes propiedades que consiguieron retener la mayor parte de sus tierras, que eran las mejores y que, tras la puesta en riego, multiplican su valor. La estructura fundiaria, por tanto, cambia en la zona, aunque siguen permaneciendo alli nueve explotaciones que superan las 100 has. y que cubren el $15 \%$ de las tierras ahora regadas. tendrán más de metro y medio de altura y cinco o seis cuadrados de superficie. A través de las puertas de los chamizos se ve la gente jornalera: hombres, mujeres y niños. Están tumbados o en cuclillas, apelotonados, guardándose del sol, esperando... (p.73)

...Hasta el mismo borde del poblado llegan los cultivos, el monocultivo gigante; el latifundio. Al parecer, nada de lo que hay en "Alfonso" pertenece a sus habitantes. Todo es prestado o alquilado, todo pertenece a las compañias agrícolas...

...Todo esto se le nota al poblado de Alfonso XIII, hay algo que indica que sus habitantes no son gente de hoz, de trabajo de sol a sol a cuenta o a jornal. Son empleados de las grandes compañias, capataces, tractoristas, conductores de camión, mecánicos de las máquinas agricolas, oficinistas; gentes que aguardan impacientes la llegada de los miles de segadores que, como una bandada de golondrinas se desparramarán por las cortijadas y factorias...

...Los viajeros ven dos peluquerias, diez o doce tabernas, dos o tres tiendas de comestibles. Una calle Ilamada del Porvenir en cuyo arranque, hasta donde llega el arrozal, unos hombres trabajan con el azadón. En la plaza, grande y bordeada con algún árbol, un grupo de niños, armados de escopetas pajareras, juegan a policias y ladrones. El cura pasea con dos guardias civiles y un paisano, dan vueltas a la plaza...(p. 81-83) 


\begin{tabular}{|l|}
\hline Investigación \\
Paisajes coloniales en el \\
Bajo Guadalquivir. Origen, \\
evolución y carácter \\
patrimonial \\
\\
Águeda A. Villa Díaz \\
Juan F. Ojeda Rivera \\
\hline
\end{tabular}

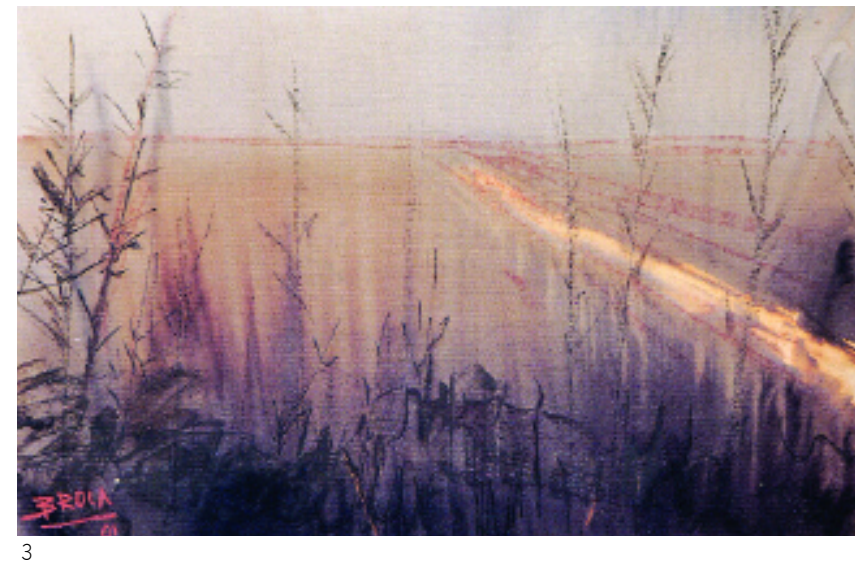

Los elementos paisajísticos más reconocibles de esta intervención colonizadora son las nuevas infraestructuras de riego -canales, acequias...- el desarrollo de terrazas correctoras de pendientes y facilitadoras del regadio - bancales o balates- $y$, sobre todo, la aparición de pueblos de nueva planta, perfectamente planificados y proyectados como núcleos poblacionales completos -lo que constituyó, sin duda, un verdadero reto para reconocidos arquitectos-, alguno de los cuales (Esquivel, proyectado por Alejandro de la Sota) destaca por su personalidad indudable en función de su original forma semicircular. Concebidas desde su nacimiento como colonias de poblamiento, estas zonas regables destacan por su vocación de permanencia y no tienen la pretensión monoproductiva de las estudiadas anteriormente, sino que pretenden constituirse en acogedoras de unas familias de colonos a las que se dotan de tierra -parcelas de 5 has.-, equipo productivo -aperos, ganadería de labor y ganado de renta- y vivienda, para que, a través del desarrollo de una agricultura familiar cubran sus economías y eleven la productividad agrícola de unos suelos relativamente fértiles. Bien es verdad que las tierras repartidas a los colonos no fueron muchas -como se ha visto- $y$, por supuesto fueron las que más dificultades tenían para ser regadas, así como que muy pronto pudieron comprobar en sus economías que las parcelas eran demasiado exiguas para sobrevivir una familia y que el ganado de renta ocupaba demasiado tiempo y resultaba poco rentable. Habia, pues, que buscar alternativas a partir de estrategias flexibles de empleo de la mano de obra familiar, lo que, por un lado, terminaba poniendo en evidencia algo implícito al propio proceso colonial y muy tradicional en la agricultura andaluza -el mantenimiento de la dependencia de la pequeña propiedad campesina respecto de la gran propiedad-, pero, por otro lado, suponía la progresiva incardinación de las familias de los colonos en la comarca que los acoge y en la cercana ciudad a través de aquellas estrategias flexibles que definen a la agricultura a tiempo parcial.
3. Paco Broca. Arrozal. Aguada sobre tela

4. Alejandro de la Sota. Poblado de Colonización de Esquivel, Sevilla. 1952-53-56-63. Fuente: Archivo del INC
En definitiva, el esquematismo planificador de la operación colonizadora condujo en poco tiempo a una situación poco dinámica y colapsada, que condenaba al colono a las peores tierras, a más trabajo, a menos ingresos y a la progresiva desarticulación de sus explotaciones (de agropecuarias a agrícolas o ganaderas), acercándolo al jornalerismo. Ante tal situación, la reacción de los colonos de segunda y tercera generación no ha sido precisamente la prevista por el plan de colonización de intensificar sus producciones -lo que hubiera llevado, probablemente, a unos cambios paisajísticos más marcados- sino la de mantener bastante extensividad y rechazar una exclusiva propuesta productivista, buscando la flexibilidad en el empleo y la ganancia externa a la parcela. En un contexto campesino y con cierta oferta de trabajo exterior, el mantenimiento de la propia explotación con una mediana capacidad productiva es un seguro de vida, pero no su único instrumento estratégico. Todo ello ha ido haciendo que el paisaje -variopinto y cambiante de cultivos anuales- se mantenga, se consolide y se vaya convirtiendo realmente en patrimonio de las nuevas generaciones de los ciudadanos de Esquivel, El Viar, Torre de la Reina o San Ignacio.

\section{A modo de conclusión}

Tras el triple recorrido efectuado y como respuesta a la interrogante inicial, sobre el posible carácter patrimonial de los paisajes descritos para los grupos humanos implicados en su construcción, puede plantearse lo siguiente a modo de conclusión:

> Todos los espacios estudiados habían sido objeto de intervenciones públicas complementadas o no por otras de compañias privadas encauzadas a su transformación y puesta en producción, con anterioridad a las colonizaciones efectuadas tras la guerra civil.

> De manera que, durante los primeros veinte años del franquismo, en su fase de autarquía y "reconstrucción nacional", se intensifican sus respectivos procesos públicos colonizadores y definitivamente, se transforman, se ponen en producción y se pueblan.

$>$ Los elementos más genuinos de estos paisajes son sus infraestructuras y sus asentamientos, que muestran claramente -y sobre todo en las colonias de explotación forestales y arrocerastanto el orden simple y lineal asociado a la recta (carreteras, canales, ringleras), como una férrea y piramidal jerarquía (organización de poblados en distintas cotas).

$>$ En la actualidad, cada uno de estos paisajes presenta una situación particular: 
> Los que surgieron de la repoblación forestal de arenales (Abalario) muestran hoy evidentes signos de disfuncionalidad y abandono, tras una historia muy marcada por etapas de iniciación, auge y decadencia. Se caracterizan por el abandono, el vacio poblacional y la decadencia, sin haber contado con tiempo para convertirse en paisajes patrimoniales porque no han adquirido la complejidad relacional e histórica, la resiliencia y la aceptación social suficientes para ser paisajes maduros y, consecuentemente, patrimonios de sus pobladores -que ya no están allí-. Aún así, su propio abandono y su desolación están generando -paradójicamente- unas percepciones creativas o "artializaciones" desde la literatura (Juan Villa -entrevistado en p.53-54-) y desde la pintura (Adolfo Piche, foto 1) que los dignifican y les otorgan una nueva y externa valoración patrimonial.

> Los paisajes agrarios de la marisma arrocera (Isla Mayor) y los de las zonas regables béticas (Viar) presentan los problemas propios de lo rural en la actualidad pero también signos de consolidación progresiva como patrimonios de unas comunidades humanas que han sabido intensificar sus producciones o elaborar estrategias múltiples que les han ido permitiendo consolidarse como poblaciones autóctonas de aquellos territorios que pasan a ser más complejos, más resilientes y más reconocidos socialmente, convirtiendo a sus paisajes en patrimonios identitarios. Las apariciones de patronímicos, los cambios de nombre (Isla Mayor por Villafranco o El Viar por Viar del Caudillo) y el desarrollo de fiestas y advocaciones locales son otras tantas expresiones de dicha patrimonialización identitaria. Pero, además, no tanto la Zona Regable de El Viar -cuyos paisajes se diferencian poco de los restantes regadíos del valle béticos- como el arrozal de la Isla del Guadalquivir -original y espectacularmente cambiante a lo largo de las estaciones- ha sido y está siendo objeto de distintas percepciones artísticas desde la literatura (Alfonso Grosso y López Salinas, véase texto literario) la pintura (Paco Broca, foto 3) y la fotografía (Atín Aya), lo que suma a su valor patrimonial identitario una artialización de gran interés y que lo proyecta hacia el exterior.

> Por último y como forma de acercarse a la memoria reciente del país, todos los poblados de los paisajes coloniales resultan en sí interesantes porque constituyen las implantaciones poblacionales completas más recientes de la historia andaluza y española. Pero, debe distinguirse entre los poblados que permanecen habitados ofrecen una imagen dinámica y viva con la adaptación y redimensionamiento de sus elementos iniciales y aquellos otros poblados abandonados, que mantienen su escala inicial y algunos de sus elementos originales más conspicuos, aportando una foto fija y sepia. Pero todos y cada uno de ellos no pueden ser entendidos más que como partes de los paisajes en los que han estado inmersos, que, en el caso del disfuncional Abalario, ha perdido sus eucaliptos, pero evoluciona de nuevo hacia un turismo verde, vinculado a Doñana y también planificado.

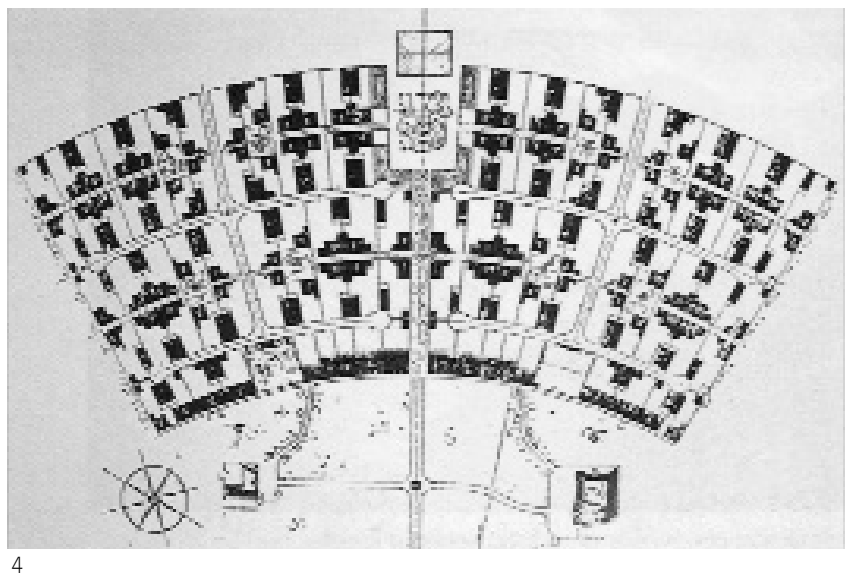

\section{Bibliografía}

AYA, A. Marismas del Guadalquivir. Catálogo de exposición fotográfica. Madrid, 2000.

BROCA, F. De sierra a mar. Catálogo de exposición de pinturas. Huelva y Sevilla, 2000.

CONVENTION européenne du paysage (Florencia, 2000) Consejo de Europa.

CRUZ, J., OJEDA, J.F. y ZOIDO, F. Explotación familiar y estrategias campesinas en los nuevos regadios béticos, en Agricultura y Sociedad, n 17, oct-dic. 1980, pp.11-68.

GONZALEZ ARTEAGA, J. Las marismas del Guadalquivir: etapas de su aprovechamiento económico. Sevilla: C.P. Antonio Cuevas. Gráficas St. María. Coria del Río, 1995.

GROSSO, A. y LÓPEZ SALINAS, A. Por el río abajo. Bilbao: Albia Literaria (2ª ed.), 1977.

MORAL ITUARTE, L. La obra hidráulica en la cuenca baja del Guadalquivir (Siglos XVIII-XX). Gestión del agua y ordenación del territorio. Sevilla, Universidad de SevillaCOPT,1991.

OJEDA RIVERA, J.F. Organización del territorio en Doñana y su entorno próximo (Almonte). Siglos XVIII- XX. Madrid: ICONA (Monografías, n 49). 1987.

OJEDA RIVERA, J. F. (Coord.). Intervenciones Públicas en el Litoral Atlántico Andaluz. Sevilla: Junta de Andalucia, Consejería de Medio Ambiente, 1993.

PÉREZ ESCOLANO, V. 50 años de arquitectura en Andalucia: 1936-1986. Sevilla: Junta de Andalucia.1986.

RODRIGUEZ CÁRDENAS, M. Historia de La Isla Mayor del rio Guadalquivir Sevilla: Colegio Público Villafranco del Guadalquivir, 1997.

ROGER, A. Court traté du paisaje. Paris: Gallimard, Bibliotheque des Sciences Humaines, 1997.

ROMERO, J.J. y ZOIDO, F. Colonización agraria en Andalucia. Sevilla: Instituto de Desarrollo Regional, Universidad de Sevilla. 1977.

VILLA DÍAZ, A.A. Paisajes de experimentación colonial en el entorno de Doñana: Cabezudos-Abalario. Sevilla: Universidad de Sevilla. Memoria de licenciatura. Inédita, 2001.

VILLA, J. Pues valdrá como ejércitos el miedo. Novela inédita, 2004. 